\title{
Addressing the double burden of the COVID-19 and noncommunicable disease pandemics: a new global governance challenge
}

Tea Collins, Juan Tello, Menno Van Hilten, Lina Mahy, Nicholas Banatvala, Guy Fones, Svetlana Akselrod, Fiona Bull, Alarcos Cieza, Jill Farrington, Jack Fisher, Cristina Gonzalez, Jaimie Guerra, Fahmy Hanna, Zsuzsanna Jakab, Alexey Kulikov, Khalid Saeed, Nisreen Abdel Latif, Bente Mikkelsen, Nasim Pourghazian, Giuseppe Troisi and Juana Willumsen (Information about the authors can be found at the end of this article.)

\section{Abstract}

Purpose - As the coronavirus disease 2019 (COVID-19) continues to spread across countries, it is becoming increasingly clear that the presence of pre-existing noncommunicable diseases (NCDs) dramatically increases the risk of aggravation in persons who contract the virus. The neglect in managing NCDs during emergencies may result in fatal consequences for individuals living with comorbidities. This paper aims to highlight the need for a paradigm shift in the governance of public health emergencies to simultaneously address NCD and noncommunicable disease $(\mathrm{CD})$ pandemics while taking into account the needs of high-risk populations, underlying etiological factors, and the social, economic, and environmental determinants that are relevant for both CDs and NCDs.

Design/methodology/approach - The paper reviews the available global frameworks for pandemic preparedness to highlight the governance challenges of addressing the dual agenda of NCDs and CDs during a public health emergency. It proposes key strategies to strengthen multilevel governance in support of countries to better prepare for public health emergencies through the engagement of a wide range of stakeholders across sectors.

Findings - Addressing both $\mathrm{CD}$ and NCD pandemics during public health emergencies requires (1) a new framework that unites the narratives and overcomes service and system fragmentations; (2) a multisectoral and multistakeholder governance mechanism empowered and resourced to include stakeholders across sectors and (3) a prioritized research agenda to understand the political economy of pandemics, the role played by different

(C) Tea Collins, Juan Tello, Menno Van Hilten, Lina Mahy, Nicholas Banatvala, Guy Fones, Svetlana Akselrod, Fiona Bull, Alarcos Cieza, Jill Farrington, Jack Fisher, Cristina Gonzalez, Jaimie Guerra, Fahmy Hanna, Zsuzsanna Jakab, Alexey Kulikov, Khalid Saeed, Nisreen Abdel Latif, Bente Mikkelsen, Nasim Pourghazian, Giuseppe Troisi and Juana Willumsen. Published by Emerald Publishing Limited. This article is published under the Creative Commons Attribution (CC BY 4.0) licence. Anyone may reproduce, distribute, translate and create derivative works of this article (for both commercial and noncommercial purposes), subject to full attribution to the original publication and authors. The full terms of this licence may be seen at http://creativecommons.org/licences/by/4.0/legalcode

Disclaimer: The authors are staff members of the World Health Organization. The authors alone are responsible for the views expressed in this article, which do not necessarily represent the decisions, policy or views of the World Health Organization.

Conflict of interest: On behalf of all authors, the corresponding author states that there is no conflict of interest.

Declaration of conflict of interest: None declared.
Double burden of the COVID-19 pandemic

Received 11 September 2020 Revised 28 October 2020 Accepted 23 November 2020 
IJHG

26,2 political systems and actors and implementation challenges, and to identify combined strategies to address the converging agendas of CDs and NCDs.

Research limitations/implications - The article is based on the review of available published evidence.

Practical implications - The uptake of the strategies proposed will better prepare countries to respond to NCD and CD pandemics during public health emergencies.

Originality/value - The article is the first of its kind addressing the governance challenges of the dual pandemic of NCDs and CDs in emergencies.

Keywords Multisectoral and multistakeholder governance, Noncommunicable diseases, Communicable diseases, COVID-19, Pandemic, International health regulations

Paper type Viewpoint

\section{Introduction}

The novel coronavirus disease (COVID-19) pandemic has been one of the most disruptive forces of the 21st century, affecting 218 countries and territories and having significant health, security, social and economic impacts. To date, the virus has infected almost 141 million individuals and resulted in over 3 million deaths (WHO, 2021).

This COVID-19 pandemic has exacerbated, and been exacerbated by, another "pandemic" caused by noncommunicable diseases (NCDs), a dual pandemic that has also negatively influenced the mental health and well-being of whole societies (United Nations, 2020). Every year, the four major groups of NCDs, that is, cardiovascular diseases, cancers, chronic respiratory diseases and diabetes, account for over 41 million deaths, equivalent to $72 \%$ of global mortality. Fifteen million of all NCD deaths are premature (between the ages 30 and 70), and $85 \%$ of this premature mortality is taking place in low- and middle-income countries (LMICs) that face a high burden of communicable diseases as well, including HIV/AIDS, malaria, tuberculosis and parasitic diseases (WHO, 2018a).

Due to their wide geographic spread, severity and lack of population immunity, NCDs constitute an ongoing pandemic, i.e. "a situation when the diseases spread over a wide area, crossing continents and affecting a large proportion of the population" (Morens et al., 2009).

In addition, NCDs are not completely noncommunicable. Many NCDs, including cardiovascular diseases, certain cancers and endocrine diseases, have long been associated with infectious risk factors. NCDs too can be transmitted from person to person, either through a viral route or by way of social networks and social, economic, commercial and environmental determinants, including food systems (Allen, 2017). More specifically, the evidence is mounting that food production, agricultural practices, transportation, urban design and land use - and their contribution to environmental degradation and zoonotic infections - are increasing susceptibility to emerging epidemics and NCDs (Swinburn et al., 2019).

As COVID-19 continues to spread across countries, it is becoming obvious that the presence of pre-existing NCDs dramatically increases the risk of aggravation in individuals who contract the virus. A recent meta-analysis revealed that hypertension, diabetes, chronic obstructive pulmonary disease (COPD), cardiovascular and cerebrovascular diseases are major risk factors for patients with COVID-19 (Wang et al., 2020). The pooled data from 35 studies showed that patients with obesity were more likely to have unfavorable outcomes, with a $48 \%$ increase in mortality (Popkin et al., 2020).

Other studies also reported that a high percentage of hospitalized patients had underlying chronic conditions, hypertension being the most common (Suleyman et al., 2020). Up to $48 \%$ of COVID-19 patients in Wuhan, $71.9 \%$ of hospitalized COVID-19 patients in New York City and $98.9 \%$ of deceased COVID-19 patients in Italy had at least one NCD (Zhou et al., 2020; Remuzzi and Remuzzi, 2020; Richardson et al., 2020).

The susceptibility to infections among individuals affected by NCDs was well documented in previous outbreaks as well, such as the Middle Eastern respiratory 
syndrome (MERS) and severe acute respiratory syndrome (SARS) (Bergman et al., 2020). Considering that more than 1.7 billion people, that is, $22 \%$ of the global population, are currently living with at least one NCD, neglecting NCDs during emergencies may have fatal consequences for individuals affected by comorbidities (Perone et al., 2017; Clark et al., 2020).

Despite available evidence that uncontrolled NCDs and their risk factors have been shown to increase the severity of other diseases and worsen health outcomes, NCD management has not been incorporated into communicable disease (CD) control efforts to build resilient health infrastructure that will function well both in normal times and during health emergencies (Kostova et al., 2017). An integrated response has been challenging partly due to the growing multipolarity and institutional fragmentation in global health over the past decades. This has led to increased competition among priorities, resulting in health silos and inconsistencies in governance processes and structures, as well as difficulties in mobilizing political commitment and resources for the complex health agenda (Held, 2019).

To be clear, there is an expanding body of literature about the convergence of NCDs and chronic CDs, such as HIV/AIDS and Tuberculosis (TB), when these conditions interact with each other and worsen health outcomes (Peer, 2015). In contrast, the evidence of increased susceptibility to CDs with pandemic potential in individuals living with NCDs, along with combined surveillance and control strategies, overarching frameworks and policies to address these overlapping disease categories, is lacking. There is also limited research on strategies to engage stakeholders beyond the health sector and on how to link infectious disease responders with the broader development and humanitarian community in public health emergencies (Held, 2019).

Amid the COVID-19 pandemic, it is increasingly clear that the multidimensional nature of health challenges calls for an expansion of global health governance in recognition that integration between initiatives to reduce NCDs and CDs can provide a sustainable foundation for emergency preparedness (Kostova et al., 2017).

In this viewpoint paper, we highlight the governance challenges of addressing the dual agenda of NCDs and communicable diseases (CDs) with pandemic potential, review the available global frameworks for pandemic preparedness with an NCD lens and propose strategies on how to strengthen multisectoral and multistakeholder governance mechanisms at all levels to help countries better prepare for public health emergencies.

\section{Broadening the public health emergency agenda}

$\mathrm{CD}$ outbreaks have been increasing over the past decade. However, not all pathogens have the potential to cause pandemics. There were a total of 418 public health events recorded in the event management system of the World Health Organization (WHO) in 2017 alone, of which $299(72 \%)$ were attributed to infectious diseases (WHO, 2018b).

Each type of event deserves its own preparedness strategy and governance structures. Influenza viruses are commonly considered for pandemic preparedness due to their regular occurrence and severity. Accordingly, the Pandemic Influenza Preparedness Framework (PIP Framework) was established in 2011 with a multisectoral and multistakeholder governance structure, including the WHO, its Member States, industry and other stakeholders for a global approach to pandemic influenza preparedness and response (WHO, 2011). However, there is a lack of guidance on the multisectoral governance structure needed to respond to CD outbreaks, other than influenza, that have pandemic potential (Shearer et al., 2020).

Nation-States play a critical role in global governance for health by coordinating their policies and collaborating to achieve common goals. Multilateralism is supported by institutions created to facilitate this type of cooperation (e.g.the WHO, other United Nations (UN) institutions and intergovernmental organizations) (Sridhar and Woods, 2013). 
IJHG

26,2

Other stakeholders in addition to governments and the UN system include non-State actors, such as philanthropic foundations, nongovernmental organizations (NGOs), public-private partnerships, professional associations, civil society organizations, academia and the private commercial sector. These actors influence global policy-making, affecting different areas of health (WHO, 2013).

Accordingly, we define governance for global health as "the use of formal and informal institutions, rules and processes by states, intergovernmental organizations, and non-state actors to deal with challenges to health that require cross-border collective action to address effectively" (Fidler, 2010).

Collaborative multisectoral and multistakeholder governance is critical to respond to emerging health challenges, including the NCD and CD syndemic, and the underlying social, economic and environmental determinants (Box 1). The need for multisectoral governance has been consistently highlighted by the high-level meetings on the prevention and control of NCDs in 2011 (UN General Assembly, 2011), 2014 (UN General Assembly, 2014) and 2018 (UN General Assembly, 2018), the 2030 Agenda for Sustainable Development (UN General Assembly, 2015), and the reinvigorated global effort to pursue Universal Health Coverage (UHC) (UN General Assembly, 2019).'

Collective efforts to address infectious disease outbreaks and NCDs will demand new governance mechanisms for multisectoral, multilevel and multistakeholder actions that align incentives for institutions and individuals to cooperate, distribute leadership, strengthen implementation processes, revise financial arrangements and encourage collaboration with non-State actors while addressing conflicts of interest and managing tradeoffs at global, regional, national and subnational levels (Rasanathan et al., 2018).

Global health governance has repeatedly fallen short of anticipating and preventing global public health challenges. Countries have invested heavily in responding to, rather than adequately preparing for, public health emergencies (Peters et al., 2019).

In low-income countries, raising the standard of health emergency preparedness to adequate levels would require an additional per capita investment of USD 4.33 in capital and USD 4.16 in recurrent costs, while corresponding capital and recurrent costs are much lower in upper- and middle-income countries standing at USD 1.35 and USD 1.41, respectively. This amounts to approximately USD 12.3 billion for all LMICs, about USD 2.48 per capita for

\section{Box 1. Multisectoral action for health}

Multisectoral governance for health is related to the movement for "intersectoral action" that arose from the Declaration of Alma Ata (1978) and encompasses all activities involving stakeholders in both health and nonhealth sectors that can potentially improve health. This may include:

Positive externalities (spillover effects) for health: Actors in nonhealth sectors (e.g. education, agriculture, transportation and environment) while conducting their core business can positively influence health, whether or not they collaborate explicitly with the health sector.

Cross-sectoral policies: Coordinated policies across different sectors can address structural forces and social norms that may affect particular vulnerable groups, or society as a whole. This includes coordinated social policies to address the social determinants of health and eliminate inequities in health. These actions exert a positive influence on CDs and NCDs and their risk factors.

Health sector-led collaborations for health: An actor within the health sector (e.g. Ministry of Health) can collaborate with other partners to directly deliver benefits to health, for example, impose higher taxes on tobacco, alcohol and sugar-sweetened beverages to discourage consumption or reduce environmental pollution to address the NCD burden.

Source: Adapted from Bennett et al. (2018), "Governing multisectoral action for health in low-income and middle-income countries: unpacking the problem and rising to the challenge," BMJ Glob Health 2018;3:e00880. 
annual operations. In comparison, the direct and indirect costs of epidemics and other emergencies are more than 20-fold higher (Peters et al., 2019). Even though the final global price tag for COVID-19 remains to be seen, pandemic diseases cost on average USD 60 billion a year and can reach USD 120 billion when economic and social costs are included (National Academy of Medicine, 2016).

Conversely, investments to roll out the WHO "best-buy" and other recommended interventions to prevent and control NCDs and increase populations' resilience to other health threats are highly cost-effective: They give a USD 7 return for every dollar invested (WHO, 2018a, b, c). Investing in good nutrition gives a return of USD 16 (Global Nutrition Report, 2014). The treatment for depression is also cost-effective, returning USD 5 on every dollar invested (WHO, 2018c).

\section{International health regulations and other global frameworks for public health emergencies}

Despite binding agreements, such as the International Health Regulations (IHR) (2005) and commitments for financing and managing health emergencies, such as the Sendai Framework for Disaster Risk UN Office for Disaster Risk Reduction, 2015-2030 (United Nations, 2015), there is a systematic lack of investments in public health emergency preparedness.

The IHR (2005) are binding for all the WHO Member States and require all state parties to develop and maintain core public health surveillance and response capacities (national legislation and policy; coordination of national focal point communications; surveillance; response; preparedness; risk communication; human resources and laboratory) and notify the WHO of all events that could potentially represent a "public health emergency of international concern." The agreement also authorizes the WHO to use information from nongovernmental sources (WHO, 2008).

By mid-2012, only $22 \%$ of the WHO Member States met the core capacity requirements of the IHR (2005). By the end of 2015 , just $35 \%$ of countries had core capacities in place (Suthar et al., 2018). To some extent, this is due to funding gaps and lack of prioritization of pandemic preparedness for NCDs, especially as part of the development assistance for health (DAH). As an example, in 2019, the world spent USD 40.6 billion in DAH. However, only USD 374 million, equivalent to less than 1\% of DAH, was provided for pandemic preparedness, against $2 \%$ of DAH allocated to NCDs (Institute for Health Metrics and Evaluation, 2018).

The Sendai Framework for Disaster Reduction (2015-2030) focuses on the shared responsibility between governments and relevant stakeholders, including non-State actors, "to play an important role as enablers in providing support to States." It aims at strengthening disaster risk governance, investing in risk reduction strategies for resilience and improving international cooperation and global partnerships (UN Office for Disaster Risk Reduction, 2015).

In 2014, the Global Health Security Agenda (GHSA) was launched to accelerate progress in achieving IHR, 2005 core capacities and to coordinate action for promoting global health security. Eighteen "action packages" have been proposed to address the three key elements of health security: prevention, detection, and response (Table 1) (WHO, 2019a).

It is worth noting that none of these global frameworks addresses NCDs in preparation for or during public health emergencies. The COVID-19 pandemic has shown the need to tackle broadly the double burden of NCDs and CDs and, consequently, review the current multisectoral and multistakeholder governance arrangements. Targeting people affected by NCDs and CDs, who experience overlapping care needs and comorbidities, calls for a concerted effort to include NCDs in public health emergency policy frameworks, preparedness plans and multisectoral governance mechanisms. 


\begin{tabular}{|c|c|c|c|}
\hline \multirow{6}{*}{$\begin{array}{l}\text { IJHG } \\
26,2\end{array}$} & \multicolumn{2}{|c|}{ Key domains } & Specific areas \\
\hline & Prevent & 1 & National legislation, policy and financing \\
\hline & & 2 & IHR coordination, communication, advocacy and reporting \\
\hline & & 3 & Antimicrobial resistance \\
\hline & & 4 & Zoonotic disease \\
\hline & & 5 & Food safety \\
\hline \multirow[t]{10}{*}{204} & & 6 & Biosafety and biosecurity \\
\hline & & 7 & Immunization \\
\hline & & 8 & Chemical events \\
\hline & & 9 & Radiation emergencies \\
\hline & & 10 & Emergency preparedness \\
\hline & Detect & 11 & National laboratory system \\
\hline & & 12 & Real-time surveillance and reporting \\
\hline & & 13 & Human resources (workforce development) \\
\hline & Respond & 14 & Emergency operation centers \\
\hline & & 15 & Linking public health with the law and multisectoral rapid response \\
\hline & & 16 & Medical countermeasures and personnel deployment \\
\hline Global health security & & 17 & Risk communication \\
\hline agenda (GHSA) & & 18 & Points of entry \\
\hline
\end{tabular}

\section{The way forward: implications for policy and advocacy}

The ongoing COVID-19 pandemic has highlighted the urgent need for a paradigm shift in public health emergency thinking to simultaneously address the concurrent agendas of NCDs and CDs, taking into account the dual needs of high-risk populations, the underlying aetiological factors, the increasing zoonotic diseases and the social, economic and environmental determinants that are relevant for both CDs and NCDs.

Despite the growing evidence linking NCDs and CDs, the two areas are often shaped by vertical programs with separate funding streams, parallel institutions and poorly aligned policies (National Academies of Sciences, Engineering, and Medicine, 2019). The current siloed governance arrangements, institutions and processes within the health sector and beyond have proved insufficient to tackle the multiple global health problems simultaneously (Smith and Lee, 2017).

The experience with COVID-19 and previous pandemics has shown that, acting alone, national governments struggle to mobilize sufficient resources and a whole-of-society response. However, collective actions can only be coordinated through multisectoral and multistakeholder governance arrangements, with the engagement of a large number of stakeholders representing different perspectives and interests across varied sectors (National Academy of Medicine, 2016).

In this context, we propose a set of key focus areas for future policy and advocacy efforts to ensure that countries better prepare for and respond to the double burden of pandemics and avoid the subsequent economic disruption.

\section{Develop a new narrative to address the convergence of NCDs and CDs in public health emergencies}

The COVID-19 crisis has highlighted that the separation of CDs and NCDs is arbitrary and that there is a need for a new narrative and combined strategies involving multiple sectors, global institutions and actors to mobilize their capacities and resources to address multifaceted health challenges. The ongoing pandemic can be framed as a public health concern, an economic and political challenge and an issue of global and national security. In all cases, an effective response strategy requires international solidarity, effective functioning of international cooperation and involvement of stakeholders within the health sector and beyond. 
Broadening the public health emergency agenda necessitates embedding NCDs into national public health emergency plans so that the public health systems can promptly respond when emergencies strike. Plans should include guidance on multisectoral partnerships, protocols for the supply of essential medicines for chronic conditions, contingency strategies for service continuity and allocation of resources for their implementation (WHO, 2020a).

Double burden of the COVID-19 pandemic

\section{Reinforce WHO's leadership in global health governance}

A unifying framework to break down the disease silos and fragmentation of health services and systems requires a collaborative effort through interconnected institutions and actors across governments, the private economic sector and civil society (Smith and Lee, 2017). The WHO is the leader in global health governance, with authority and mandate derived from its constitution. The WHO provides stewardship on all health areas and uses its convening power to bring stakeholders together, including UN agencies, Member States, and NSAs, to develop the necessary technical tools and oversee the implementation of IHR and other global frameworks (Box 2).

However, as a Member State-led institution, the WHO has its limitations, which are compounded by a persistent funding gap (the zero-nominal growth policy of WHO's funding), which hampers the organization's ability to maintain its autonomy and coordinate other highly resourced state agencies, as well as non-State actors with divergent priorities (Reddy et al., 2018). The WHO's recent renewed focus on multisectoral action due to the alignment of its new General Programme of Work (GPW 13) with the 2030 Agenda for Sustainable Development, along with adopting UHC as an umbrella goal, provides a window of opportunity to reinforce WHO's role of institutional leadership of the global health agenda and to garner political will for increased financial contributions to allow for strategic allocation of flexible resources (Reddy et al., 2018).

\section{Secure adequate funds}

With the introduction of the interconnected 2030 Agenda for Sustainable Development (UN General Assembly, 2015), the momentum to finance intersectoral action is growing. One commonly used approach is to dedicate funds from health budgets for intersectoral activities for agreed health objectives. Another practical approach is to have a joint budgeting process involving multiple sectors.

These approaches can be effectively leveraged to address NCDs and CDs in pandemic preparedness plans (Jakovljevic et al., 2019). However, during the pandemic, development assistance funding will also be necessary.

\section{Box 2. The WHO's six core functions are as follows:}

(1) Providing leadership on matters critical to health and engaging in partnerships where joint action is needed;

(2) Shaping the research agenda and stimulating the generation, translation and dissemination of valuable knowledge;

(3) Setting norms and standards and promoting and monitoring their implementation;

(4) Articulating ethical and evidence-based policy options;

(5) Providing technical support, catalyzing change and building sustainable institutional capacity;

(6) Monitoring the health situation and assessing health trends.

Source: World Health Organization's Thirteenth General Programme of Work 2019-2023: Promote Health, Keep the World Safe, Serve the Vulnerable. WHO, Geneva, 2019b. 
IJHG

26,2

206

The World Bank Group has committed up to USD 160 billion to mitigate the health, economic and social shocks that countries are experiencing due to COVID-19 (World Bank, 2020). The International Monetary Fund (IMF) is currently making about USD 250 billion, a quarter of its USD 1 trillion lending capacity, available to its member states (IMF, 2020). Similarly, the Group of Twenty (G20) has committed to "act decisively and contribute USD21 billion to fight the pandemic" (G20 Saudi Arabia, 2020).

The newly launched Global Collaboration to Accelerate the Development, Production and Equitable Access to New COVID-19 Diagnostics, Therapeutics and Vaccines, initiated by a group of global health actors (The Bill and Melinda Gates Foundation, Coalition for Epidemic Preparedness Innovation, Gavi, Global Fund, Unitaid, Wellcome Trust, and WHO), together with private sector partners and other stakeholders, is also promising (WHO, 2020b). However, these initiatives need to incorporate strategies to reach key populations experiencing converging COVID-19 and NCD risks to address their overlapping needs. Drawing from the experience with influenza vaccines, as well as with vaccines for tetanus, hepatitis $A$ and $B$, and rabies, concerns have been raised that vaccines against COVID-19 may not be as effective in individuals with certain underlying conditions, such as overweight/ obesity (Painter et al., 2015; Popkin et al., 2020).

\section{Translate global commitments into national stewardship}

Developing multisectoral policies and plans for public health emergencies is a political process and requires strengthening the capacities of ministries of health linked to governance functions, such as stewardship, regulation, resource management, citizen empowerment and complex relationships with relevant stakeholders from health and nonhealth sectors in both the government and nongovernment sectors (Wickramasinghe et al., 2018).

In addition, some countries may establish and institutionalize multisectoral coordination platforms/mechanisms as part of their governance structures. The multisectoral coordination mechanisms should define methods for coordinating different relevant sectors, but maintain ownership of existing critical structures, such as emergency operations centers, which are typically managed by the public sector (Agbo et al., 2019).

To ensure the highest-level political commitment, national multisectoral coordination mechanisms can be anchored in the president's or prime minister's office. However, the arrangements may vary from country to country. For example, Uganda decided to institute a rotating coordinating system, drawing from its success in controlling Trypanosomiasis. Guinea, Liberia and Sierra Leone instituted multisectoral coordination platforms to address gaps in public health emergency preparedness and response identified during the 2014-2016 Ebola crisis and made the platforms part of the permanent national government structures (Agbo et al., 2019).

There is also a growing interest in accountable communities for health (ACHs) governance models, when communities embrace a multisectoral approach to health with a centralized infrastructure (e.g. health department), common agenda, shared measurement strategies, continuous communication and mutually reinforcing activities. Sectors engaged in ACHs typically include businesses, healthcare delivery, public health, transportation, education, finance, housing and community-based organizations (Mongeon et al., 2017).

Regional governance [e.g. the Association of Southeast Asian Nations (ASEAN), the Caribbean Community (CARICOM) and the African Union (AU)] will also be critical to spur action against common health threats. Regional collaboration has tremendous potential to help translate global commitments into national implementation. Regional leadership and coordination can also help compensate for the lack of resources, both human and financial, at the national level. 
Engage with civil society for greater accountability

Civil society can ascertain needs and transform them into demands by influencing the priorities of the health agenda; advocate for repositioning health issues based on societal values; voice and mobilize the agenda of those left behind; participate in legislative design and policy implementation and play a watchdog role to hold stakeholders accountable.

However, some civil society organizations are narrowly focused on particular policy issues, such as tobacco control, and there is often a lack of coordination across issues, particularly CDs and NCDs (Gomez, 2018). Going forward, there is a unique opportunity to engage civil society, including academic scholars, religious leaders and actors across sectors, in supporting an integrated response to $\mathrm{NCD}$ and $\mathrm{CD}$ pandemics preparedness, identifying knowledge and funding gaps, and proposing context-specific scalable solutions.

It will also be important to engage people living with NCDs along with their informal carers, who often themselves suffer from one or more NCDs, and explore the major challenges they face, including the economic consequences of chronic illness and a higher vulnerability during public health emergencies (Leeder, 2018).

\section{Manage diverging interests}

Broadening the NCD agenda from the four-by-four agenda (four risk factors, including tobacco use, harmful use of alcohol, unhealthy diets and physical inactivity, and four diseases encompassing cardiovascular diseases, cancers, chronic obstructive pulmonary disease and diabetes) to the five-by-five framework (to include environmental pollution and mental health), has increased opportunities for more actors from both the public and private sectors to achieve synergies among different causes to protect a public good while putting essential safeguards in place to manage potential conflicts of interest (Collins et al., 2019).

The pandemic has also illustrated that the globalized economy and the transnational mobility of large corporations cannot be managed by national-level regulations. Global governance is needed, including regulatory capacities, international trade and investment agreements (Swinburn et al., 2019). Communication and coordination with the pharmaceutical and food industries are particularly important where crisis and emergency responses are required.

\section{Implement learning and feedback loops}

Multisectoral and multistakeholder governance requires close monitoring and evaluation mechanisms to ensure that stakeholders create shared public value. Actual events present an opportunity to learn how well preparedness systems perform in real-world settings and address gaps in national and global public health preparedness. The WHO recommends After Action Reviews to be conducted within three months of the end of an event, adopting a "whole-of-society" approach to include relevant public and private sector partners, depending on the context. After Action Reviews provide experiential learning opportunities and document both successes and failures, ensuring improved performance during future responses. The After Action Reviews have recently been included in the IHR Monitoring and Evaluation Framework to facilitate the sharing of best practices (Stoto et al., 2019).

\section{Enhancement of research for improved governance for public health emergency preparedness and response}

While the COVID-19 pandemic is still a threat, it also creates an opportune time to start the development of a common research agenda. From a governance perspective, research priorities may include the political economy of pandemics, the role played by different
Double burden of the COVID-19 pandemic 
IJHG

26,2

political systems (e.g. autocratic vs democratic), the influence of health services and systems (e.g. centralized vs decentralized) in responding to pandemics, the trade-offs between national security/safety and citizens' rights, and public health capacities and approaches (e.g. population-based prevention strategies vs clinical care) (Bal et al., 2020).

There is also a need to focus on expanding research to investigate the etiology of comorbidities, identify therapies for patients with co-occurring diseases, design and implement disease surveillance systems for comorbid conditions, retrain healthcare workers to simultaneously handle multiple diseases and reorient public health systems to prevent complex health conditions (Magee et al., 2017).

\section{References}

Agbo, S., Gbaguidi, L., Biliyar, C., Sylla, S., Fahnbulleh, M., Dogba, J., Keita, S., Kamara, S., Jambai, A., Harris, A., Nyenswah, T., Seni, M., Bhoye, S., Sambe, D. and Kitua, A. (2019), "Establishing national multisectoral coordination and collaboration mechanisms to prevent, detect, and respond to public health threats in Guinea, Liberia, and Sierra Leone 2016-2018", One Health Outlook, Vol. 1, p. 4, doi: 10.1186/s42522-019-0004-z.

Allen, L. (2017), “Are we facing a noncommunicable disease pandemic?", Journal of Epidemiology and Global Health, Vol. 7 No. 1, pp. 5-9, doi: 10.1016/j.jegh.2016.11.001.

Bal, R., de Graaff, B., van de Bovenkamp, H. and Wallenburg, I. (2020), "Practicing Corona - towards a research agenda of health policies”, Health Policy, Vol. 124 No. 7, pp. 671-673, doi: 10.1016/j. healthpol.2020.05.010.

Bennett, S., Glandon, D. and Rasanathan, K. (2018), "Governing multisectoral action for health in lowincome and middle-income countries: unpacking the problem and rising to the challenge", BMJ Global Health, Vol. 3, e000880.

Bergman, M., Jagannathan, R. and Narayan, K.M.V. (2020), "Nexus of COVID-19 and diabetes pandemics: global public health lessons”, Diabetes Research and Clinical Practice, Vol. 164, 108215, doi: 10.1016/j.diabres.2020.108215.

Clark, A., Jit, M., Warren-Gash, C., Guthrie, B., Wang, H.H.X., Mercer, S.W., Sanderson, C., McKee, M., Troeger, C., Ong, K.L., Checchi, F., Perel, P., Joseph, S., Gibbs, H.P., Banerjee, A. and Eggo, R.M. (2020), "Global, regional, and national estimates of the population at increased risk of severe COVID-19 due to underlying health conditions in 2020: modelling study", Lancet Global Health, Vol. 8, pp. e1003-e1017.

Collins, T., Mikkelsen, B. and Akselrod, S. (2019), "Interact, engage or partner? Working with the private sector for the prevention and control of noncommunicable diseases", Cardiovascular Diagnosis and Therapy, Vol. 9 No. 2, pp. 158-164, doi: 10.21037/cdt.2018.08.04.

Declaration of Alma-Ata, International Conference on Primary Health Care (1978), available at: https:// www.who.int/teams/social-determinants-of-health/declaration-of-alma-ata (accessed 21 April 2021).

Fidler, D.P. (2010), The Challenges of Global Health Governance, Council on Foreign Relations, United States of America, available at: https://www.cfr.org/report/challenges-global-health-governance (accessed 8 September 2020).

G20 Saudi Arabia 2020 (2020), "G20 contributes over $\$ 21$ billion to fight COVID-19", available at: https:/g20.org/en/Pages/CombatCOVID19.aspx (accessed 31 July 2020).

Global Nutrition Report (2014), “2014 global nutrition report”, available at: https:// globalnutritionreport.org/reports/2014-global-nutrition-report/ (accessed 3 August 2020).

Gomez, E. (2018), "Civil society in global health policymaking: a critical review", Global Health, Vol. 14, p. 73, doi: 10.1186/s12992-018-0393-2.

Held, D. (2019), "Gridlock, innovation and resilience in global health governance”, Global Policy, Vol. 10 No. 2, doi: 10.1111/1758-5899.12654. 
Institute for Health Metrics and Evaluation (2018), "Financing global health 2017: funding universal health coverage and the unfinished HIV/AIDS agenda", available at: http://www.healthdata.org/ policy-report/financing-global-health-2017 (accessed 8 September 2020).

International Monetary Fund (2020), "COVID-19 financial assistance and debt service relief”, available at: https://www.imf.org/en/Topics/imf-and-covid19/COVID-Lending-Tracker (accessed 31 July 2020).

Jakovljevic, M., Jakab, M., Gerdtham, U., McDaid, D., Oguru, S., Varavikova, E., Merrick, J., Adany, R., Okunade, A. and Gretzen, T.E. (2019), "Comparative financing analysis and political economy of noncommunicable disesaes", Journal of Medical Economics, Vol. 22 No. 8, pp. 722-727, doi: 10. 1080/13696998.2019.1600523.

Kostova, D., Husain, M.J., Sugerman, D., Hong, Y., Saraiya, M., Keltz, J. and Asma, S. (2017), "Synergies between communicable and noncommunicable disease programs to enhance global health security", Emerging Infectious Diseases, Vol. 23, doi: 10.3201/eid2313.170581.

Leeder, S.R. (2018), "The experiences of patients and carers living with multimorbid, noncommunicable diseases", The Royal Australian College of General Practitioners, Vol. 47, pp. 1-2.

Magee, M., Ali, M., Prabhakaran, D., Ajay, V.S. and Narayan, K.M.V. (2017), "Integrated public health and health service delivery for noncommunicable diseases and comorbid infectious diseases and mental health", In: Prabhakaran, D., et al. (Eds), Cardiovascular, Respiratory, and Related Disorders, 3rd ed., The International Bank for Reconstruction and Development / The World Bank, Washington (DC), Chapter 16. available at: https:/www.ncbi.nlm.nih.gov/books/ NBK525148/ doi: 10.1596/978-1-4648-0518-9_ch16.

Mongeon, M., Jeffrey, L. and Heinrich, J. (2017), Elements of Accountable Communities for Health, Discussion Paper, National Academy of Medicine, available at: https://nam.edu/elements-ofaccountable-communities-for-health-a-review-of-the-literature/ (accessed 25 October 2020).

Morens, D.M., Fokers, G.K. and Fauci, A.S. (2009), "What is a pandemic?", The Journal of Infectious Diseases, Vol. 200 No. 7, pp. 1018-21, doi: 10.1086/644537.

National Academies of Sciences, Engineering, and Medicine (2019), The Convergence of Infectious Diseases and Noncommunicable Diseases: Proceedings of a Workshop, The National Academies Press, Washington, D.C.

National Academy of Medicine (2016), The Neglected Dimension of Global Security: A Framework to Counter Infectious Disease Crises, The National Academies Press, Washington (DC), available at: https://nam.edu/wp-content/uploads/2016/01/Neglected-Dimension-of-GlobalSecurity.pdf.

Painter, S.D., Ovsyannikova, I.G. and Poland, G.A. (2015), "The weight of obesity on the human immune response to vaccination", Vaccine, Vol. 33, pp. 4422-4429.

Peer, N. (2015), "The converging burdens of infectious and non-communicable diseases in rural-tourban migrant Sub-Saharan African populations: a focus on HIV/AIDS, tuberculosis and cardio-metabolic diseases”, Tropical Diseases, Travel Medicine and Vaccines, Vol. 1, p. 6, doi: 10. 1186/s40794-015-0007-4.

Perone, S.A., Martinez, E., du Mortier, S., Rossi, R., Pahud, M., Urbaniak, V., Chappius, F., Hagon, O., Bausch, F.J. and Beran, D. (2017), "Non-communicable diseases in humanitarian settings: ten essential questions", Conflict and Health, Vol. 11, p. 17, doi: 10.1186/s13031-017-0119-8.

Peters, D.H., Hanssen, O., Gutierrez, J., Abrahams, J. and Nyenswah, T. (2019), "Financing common goods for health: core government functions in health emergency and disaster risk management", Health Systems and Reform, Vol. 5 No. 4, pp. 307-321, doi: 10.1080/23288604. 2019.1660104.

Popkin, B.M., Du, S., Green, W.D., Beck, M.A., Algaith, T., Herbst, C.H., Alsukait, R.F., Alluhidan, M., Alazemi, N. and Shekar, M. (2020), "Individuals with obesity and COVID-19: a global perspective on the epidemiology and biological relationships", Obesity Reviews, Vol. 21, e13128, doi: 10.1111/obr.13128.
Double burden of the COVID-19 pandemic 
IJHG

26,2

Rasanathan, K., Atkins, V., Mwansambo, C., Soucat, A. and Bennett, S. (2018), "Governing multisectoral action for health in low- and middle-income countries: an agenda for the way forward", BMJ Global Health, Vol. 3, e000890.

Reddy, S.K., Mazhar, S. and Lencucha, R. (2018), "The financial sustainability of the World Health Organization and the political economy of global health governance: a review of funding proposals", Globalization and Health, Vol. 14, p. 119, doi: 10.1186/s12992-018-0436-8.

Remuzzi, A. and Remuzzi, G. (2020), “COVID-19, and Italy: what next?", Lancet, Vol. 395 No. 10231, pp. 1225-1228, available at: https://www.ncbi.nlm.nih.gov/pubmed/32178769, doi: 10.1016/ S0140-6736(20)30627-9 (published online 12 March 2020, (accessed 8 September 2020).

Richardson, S., Hirsch, J.S., Narasimhan, M., Crawford, J.M., McGinn, T. and Davidson, K.W. (2020), Presenting Characteristics, Comorbidities, and Outcomes Among 5,700 Patients Hospitalized with COVID-19 in the New York City Area, Original Investigation, JAMA Network Open, published online 24 April 2020. available at: https:/jamanetwork.com/journals/jama/fullarticle/ 2765184 (accessed 8 September 2020), doi: 10.1001/jama.2020.6775.

Shearer, F.M., Moss, R., McVernon, J., Ross, J.V. and McCaw, J.M. (2020), "Infectious disease pandemic planning and response: incorporating decision analysis", PLoS Medicine, Vol. 17 No. 1, e1003018, doi: 10.1371/journal.pmed.1003018.

Smith, R. and Lee, K. (2017), "Global health governance: we need innovation, not renovation”, BMJ Global Health, Vol. 2, e000275, doi: 10.1136/bmjgh-2016-000275.

Sridhar, D. and Woods, N. (2013), "Trojan multilateralism: global cooperation in health", Global Policy, Vol. 4 No. 4, pp. 325-335, doi: 10.1111/1758-5899.12066.

Stoto, M.A., Nelson, C., Piltch-Loeb, R., Mayigane, L.N., Cooper, F. and Chungong, S. (2019), "Getting the most from after-action reviews to improve global health security", Globalization and Health, Vol. 15, p. 58, doi: 10.1186/s12992-019-0500-z.

Suleyman, G., Fadel, R.A., Malette, K.M., Hammond, C., Abdulla, H., Entz, A., Demertzis, Z., Hanna, Z., Failla, A., Dagher, C., Chaudhry, Z., Vahia, A., Lanfranco, O.A., Ramesh, M., Zervos, M.J., Alangaden, G., Miller, J. and Brar, I. (2020), "Clinical characteristics and morbidity associated with coronavirus disease 2019 in a series of patients in Metropolitan Detroit", JAMA Network Open, Vol. 3 No. 6, doi: 10.1001/jamanetworkopen.2020.10895.

Suthar, A.B., Allen, L.G., Cifuentes, S., Dye, C. and Nagata, J.M. (2018), "Lessons learnt from the implementation of the international health regulations: a systematic review", Bulletin of the World Health Organization, Vol. 96, pp. 110-121, doi: 10.2471/BLT.16.189100.

Swinburn, B.A., Kraak, V.I., Allender, S., Atkins, V.J., Baker, P.I., Bogard, J.R., Brinsden, H., Calvillo, A., de Schutter, O., Devarajan, R., Ezzaati, M., Friel, S., Goenka, S., Hammond, R.A., Hastings, G., Hawkes, C., Herrero, M., Hovmand, P.S., Howden, M., Jaacks, L.M., Kapetanaki, A.B., Kasman, M., Kuhnlein, H.V., Kumanyika, S.K., Larijani, B., Lobstein, T., Long, M.W., Matsudo, V.K.R., Mills, S.D.H., Morgan, G., Morshed, A., Nece, P.M., Pan, A., Patterson, D.W., Sacks, G., Shekar, M., Simmons, G.I., Smit, W., Tootee, A., Vandevijvere, S., Waterlander, W.E., Wolfenden, L. and Dietz, W.H. (2019), "The global syndemic of obesity, undernutrition, and climate change: the Lancet commission report”, The Lancet, Vol. 393 No. 10173, pp. 791-846, doi: 10.1016/S0140-6736(18)32822-8.

UN General Assembly (2011), "Political declaration of the high-level meeting of the general assembly on the prevention and control of non-communicable diseases", A/Res/66/2. available at: https:// www.who.int/nmh/events/un_ncd_summit2011/political_declaration_en.pdf?ua =1 (accessed 3 August 2020).

UN General Assembly (2014), "The outcome document of the high-level meeting of the general assembly on the comprehensive review and assessment of the progress achieved in the prevention and control of non-communicable diseases", A/Res/68/300. available at: https://www. who.int/nmh/events/2014/a-res-68-300.pdf?ua =1 (accessed 3 August 2020).

UN General Assembly (2015), "Transforming our world: the 2030 agenda for sustainable development”, A/Res/70/1. available at: https://www.un.org/ga/search/view_doc.asp? symbol=A/RES/70/1\&Lang $=\mathrm{E}$ (accessed 5 July 2020). 
UN General Assembly (2018), "Political declaration of the third high-level meeting of the general assembly on the prevention and control of non-communicable diseases", A/Res/72/2. available at: https://digitallibrary.un.org/record/1648984? ln=en (accessed 3 August 2020).

UN General Assembly (2019), "Political declaration of the high-level meeting on universal health coverage: universal health coverage: moving together to build a healthier world", available at: https://undocs.org/en/A/RES/74/2 (accessed 3 August 2020).

UN Office for Disaster Risk Reduction (2015), "Sendai framework for disaster risk reduction 20152030", available at: https://www.undrr.org/publication/sendai-framework-disaster-riskreduction-2015-2030.

United Nations (2015), "Sendai framework for disaster risk reduction 2015-2030", available at: https:// www.preventionweb.net/files/43291_sendaiframeworkfordrren.pdf (accessed 25 October 2020).

United Nations (2020), "Policy brief: COVID-19 and the need for action on mental health", available at: https://www.un.org/sites/un2.un.org/files/un_policy_brief-covid_and_mental_health_final.pdf (accessed 1 July 2020).

Wang, B., Li, R., Lu, Z. and Huang, Y. (2020), "Does comorbidity increase the risk of patients with COVID-19: evidence from a meta-analysis”, Ageing, Vol. 12 No. 7, pp. 6049-6057, doi: 10.18632/ aging.103000.

WHO (2008), "International health regulations (2005) - second edition”, available at: https://www.who. int/ihr/publications/9789241596664/en/.

WHO (2011), "Pandemic influenza preparedness: sharing of influenza viruses and access to vaccine sand other benefits", available at: https://apps.who.int/iris/bitstream/handle/10665/44796/ 9789241503082_eng.pdf;jsessionid=CFFB2864D74CF18763D83E014379ABE2? sequence $=1$ (accessed 20 October 2020).

WHO (2013), "WHO's role in global health governance. Report by the director-general", EB 132/5 Add.5. available at: https://apps.who.int/iris/handle/10665/78607 (accessed 8 September 2020).

WHO (2018a), "Global health estimates 2016: deaths by cause, age, sex, by country and by region, 2000-2016”, Geneva. available at: https://www.who.int/healthinfo/global_burden_disease/ estimates/en/ (accessed 27 October 2020).

WHO (2018b), "Implementation of the international health regulations (2005). Annual report on the implementation of the international health regulations", Seventy-First World Health Assembly, A71/7. available at: https://apps.who.int/gb/ebwha/pdf_files/WHA71/A71_7-en.pdf (accessed 20 October 2020).

WHO (2018c), "Timeto deliver:report of the WHO independent high-level commission on noncommunicable diseases", available at: https:/www.who.int/ncds/management/time-to-deliver/en/.

WHO (2019a), "WHO benchmarks for international health regulations (IHR) capacities", available at: https://ghsagenda.org/2020/07/16/who-benchmarks-for-international-health-regulations-ihrcapacities-2019/ (accessed 4 August 2020).

WHO (2019b), "Thirteenth general programme of work 2019-2023: promote health, keep the world safe, serve the vulnerable", available at: https:/apps.who.int/iris/bitstream/handle/10665/ 324775/WHO-PRP-18.1-eng.pdf (accessed 22 April 2021).

WHO (2021), available at: https://www.who.int/emergencies/diseases/novel-coronavirus-2019 (accessed 18 April 2021).

WHO (2020a), "Maintaining essential health services: operational guidance for the COVID-19 context", available at: https://www.who.int/publications/i/item/WHO-2019-nCoV-essential-healthservices-2020.1 (accessed 24 October 2020).

WHO (2020b), "Access to COVID-19 tools (act) accelerator: a global collaboration to accelerate the development, production and equitable access to new COVID-19 diagnostics, therapeutics and vaccines", available at: file:///C:/Users/Collinst/AppData/Local/Temp/access-to-covid-19-tools(act)-accelerator-call-to-action-24april2020.pdf (accessed 24 October 2020). 
$\mathrm{IJHG}$

26,2

\section{2}

Wickramasinghe, K., Wilkins, E., Foster, C., Fadhil, I., Hammerich, A., Slama, S., El Berri, H., Elimam, M., Adib, S., Al-Mudwahi, M. and Townsend, N. (2018), "The development of national multisectoral action plans for the prevention and control of noncommunicable diseases: experiences of national-level stakeholders in four countries", Global Health Action, Vol. 11 No. 1, 1532632, doi: 10.1080/16549716.2018.1532632.

World Bank (2020), "How the world bank group is helping countries with COVID-19", available at: https://www.worldbank.org/en/news/factsheet/2020/02/11/how-the-world-bank-group-ishelping-countries-with-covid-19-coronavirus (accessed 31 July 2020).

Zhou, F., Yu, T., Du, R., Fan, G., Liu, Y., Liu, Z., Xiang, J., Wang, Y., Song, B., Gu, X., Guan, L., Wei, Y., Li, H., Wu, X., Xu, J., Tu, S., Zhang, Y., Chen, H. and Cao, B. (2020), "Clinical course and risk factors for mortality of adult inpatients with COVID-19 in Wuhan, China: a retrospective cohort study”, Lancet, Vol. 395 No. 10229, pp. 1054-1062, doi: 10.1016/S0140-6736(20)30566-3.

\section{Author Affiliations}

Tea Collins, World Health Organization, Geneva, Switzerland

Juan Tello, World Health Organization, Geneva, Switzerland

Menno Van Hilten, World Health Organization, Geneva, Switzerland

Lina Mahy, World Health Organization, Geneva, Switzerland

Nicholas Banatvala, World Health Organization, Geneva, Switzerland

Guy Fones, World Health Organization, Geneva, Switzerland

Svetlana Akselrod, World Health Organization, Geneva, Switzerland

Fiona Bull, World Health Organization, Geneva, Switzerland

Alarcos Cieza, World Health Organization, Geneva, Switzerland

Jill Farrington, World Health Organization Regional Office for Europe, Copenhagen, Denmark

Jack Fisher, World Health Organization, Geneva, Switzerland

Cristina Gonzalez, World Health Organization, Geneva, Switzerland

Jaimie Guerra, World Health Organization, Geneva, Switzerland

Fahmy Hanna, World Health Organization, Geneva, Switzerland

Zsuzsanna Jakab, World Health Organization, Geneva, Switzerland

Alexey Kulikov, World Health Organization, Geneva, Switzerland

Khalid Saeed, World Health Organization Regional Office for the Eastern Mediterranean, Cairo, Egypt

Nisreen Abdel Latif, World Health Organization Regional Office for the Eastern Mediterranean, Cairo, Egypt

Bente Mikkelsen, World Health Organization, Geneva, Switzerland

Nasim Pourghazian, World Health Organization Regional Office for the Eastern Mediterranean, Cairo, Egypt

Giuseppe Troisi, World Health Organization, Geneva, Switzerland

Juana Willumsen, World Health Organization, Geneva, Switzerland

\section{Corresponding author}

Tea Collins can be contacted at: collinst@who.int

For instructions on how to order reprints of this article, please visit our website:

www.emeraldgrouppublishing.com/licensing/reprints.htm

Or contact us for further details: permissions@emeraldinsight.com 